\title{
Topical negative pressure therapy of a sternotomy wound increases sternal fluid content but does not affect internal thoracic artery blood flow: Assessment using magnetic resonance imaging
}

\author{
Rainer Petzina, MD, ${ }^{\mathrm{a}, \mathrm{d}}$ Martin Ugander, MD, PhD, ${ }^{\mathrm{b}}$ Lotta Gustafsson, MSc, PhD, ${ }^{a}$ Henrik Engblom, MD, PhD, ${ }^{\mathrm{b}}$ \\ Roland Hetzer, MD, PhD, ${ }^{d}$ Håkan Arheden, $\mathrm{MD}, \mathrm{PhD}^{\mathrm{b}}$ Richard Ingemansson, MD, PhD, ${ }^{\mathrm{c}}$ and Malin Malmsjö, MD, $\mathrm{PhD}^{\mathrm{a}}$
}

From the Departments of Medicine, ${ }^{\text {a }}$ Clinical Physiology, and Cardiothoracic Surgery, ${ }^{\mathrm{c}}$ Lund University Hospital, Lund, Sweden, and Deutsches Herzzentrum Berlin, ${ }^{\mathrm{d}}$ Berlin, Germany.

This study was supported by the Åke Wiberg Foundation, the M. Bergvall Foundation, the Swedish Medical Association, the Royal Physiographic Society in Lund, the Swedish Medical Research Council, the Crafoord Foundation, the Swedish Heart-Lung Foundation, the Swedish Government Grant for Clinical Research, and the Swedish Hypertension Society.

Received for publication May 28, 2007; revisions received Aug 9, 2007; accepted for publication Sept 12, 2007.

Address for reprints: Malin Malmsjö, MD, $\mathrm{PhD}$, Vascular Research, Lund University, BMC A13, SE-221 84 Lund, Sweden (E-mail: malin.malmsjo@med.lu.se).

J Thorac Cardiovasc Surg 2008;135:100713

$0022-5223 / \$ 34.00$

Copyright $(\subset 2008$ by The American Association for Thoracic Surgery

doi:10.1016/j.jtcvs.2007.09.070
Objective: Topical negative pressure therapy has excellent healing effects in poststernotomy mediastinitis. Topical negative pressure therapy reduces bacterial counts, increases wound edge microvascular blood flow and granulation tissue formation, and facilitates healing. No study has yet been performed to examine the effect of topical negative pressure on the blood and fluid content in the sternal bone marrow, which is a crucial component in osteitis.

Methods: Eight pigs underwent median sternotomy, left internal thoracic artery harvesting, followed by topical negative pressure treatment. Magnetic resonance imaging was used to quantify both tissue fluid and/or blood content (T2-weighted short tau inversion recovery [T2-STIR]) and internal thoracic artery blood flow (flow quantification).

Results: Before application of topical negative pressure, the T2-STIR signal intensity ratio was lower for the left than for the right hemisternum (left, 1.3; right, 2.6), indicating lower levels of tissue fluid content on the left, devascularized side. On application of topical negative pressure, the T2-STIR signal intensity ratio increased immediately for both the sternal bone and the pectoral muscle (left hemisternum after 4 minutes of topical negative pressure: 2.3), leveled off after 4 minutes, and remained unchanged for the ensuing 40 minutes, suggesting movement of fluid and/or blood into the tissue of the wound edge. Topical negative pressure did not affect blood flow in the right internal thoracic artery.

Conclusions: T2-STIR measurements show that topical negative pressure increases sternotomy wound edge tissue fluid and/or blood content. Topical negative pressure creates a pressure gradient that presumably draws fluid from the surrounding tissue to the sternal wound edge and into the vacuum source. This "endogenous drainage" may be one possible mechanism by which osteitis is resolved by topical negative pressure in poststernotomy mediastinitis.

$\mathrm{D}$ eep sternal wound infection, also called mediastinitis, is a disastrous complication for patients undergoing cardiac surgery. The overall incidence of poststernotomy mediastinitis is usually between $1 \%$ and $3 \%^{1-3}$ and is associated with a mortality, between $10 \%$ and $35 \%$. $^{1-6}$ The conventional treatment in poststernotomy mediastinitis is surgical revision, continuous irrigation with drainage, ${ }^{7}$ or wound closure with vascularized soft tissue flaps, for example, greater omentum ${ }^{8}$ or muscle flaps. ${ }^{9}$

Topical negative pressure (TNP) therapy is a recently introduced technique in wound care, including poststernotomy mediastinitis. ${ }^{10}$ The beneficial effects of TNP therapy of sternotomy wounds includes sternal stabilization, ${ }^{11}$ early mobilization of the patient, lower rates of recurrent mediastinitis, ${ }^{12}$ shorter length of hospital 


$$
\begin{array}{ll}
\text { Abbreviations and Acronyms } \\
\begin{aligned}
\text { ITA } & =\text { internal thoracic artery } \\
\text { MRI } & =\text { magnetic resonance image(ing) } \\
\text { ROI } & =\text { region of interest } \\
\text { SENSE } & =\text { SENSitivity Encoding } \\
\text { T2-STIR } & =\text { T2-weighted short tau inversion recovery } \\
\text { TE } & =\text { echo time } \\
\text { TNP } & =\text { topical negative pressure } \\
\text { TR } & =\text { repetition time }
\end{aligned}
\end{array}
$$

stay, ${ }^{13}$ an improved 90-day survival, and an excellent longterm survival. ${ }^{14,15}$ The mechanisms by which TNP facilitates healing of wounds include continuous drainage of exudates, reduction in bacterial counts, enhanced granulation tissue formation, and increased microvascular blood flow to adjacent soft tissue. ${ }^{16-19}$

In the sternotomy wound, osteitis is one of the major complicating factors. No study has yet been performed to examine the effect of TNP on the sternal bone. We hypothesized that TNP has effects on the sternal bone fluid and/or blood content, and these effects may be pivotal in accelerating the healing of poststernotomy mediastinitis. The aims of the present study were therefore to investigate the effect of TNP therapy on (1) sternal wound edge fluid content assessed by T2-weighted short tau inversion recovery (STIR) magnetic resonance imaging (MRI) tissue characterization and (2) blood flow in the internal thoracic artery (ITA) assessed by MRI flow quantification.

\section{Material and Methods \\ Animals}

An uninfected porcine sternotomy wound model was used for the present study. Eight domestic Landrace pigs of both sexes, with a mean body weight of $50 \mathrm{~kg}$, were fasted overnight with free access to water. The study was approved by the Ethics Committee for Animal Research, Lund, Lund University, Sweden. The investigation complied with the "Guide for the Care and Use of Laboratory Animals" as recommended by the US National Institutes of Health and published by the National Academic Press (1996).

\section{Anesthesia and Surgical Procedure}

Anesthesia was induced by an intramuscular injection of ketamine (Ketaminol vet $100 \mathrm{mg} / \mathrm{mL}$; Farmaceutici Gellini S.p.A, Aprilia, Italy) $15 \mathrm{mg} / \mathrm{kg}$ body weight, in combination with xylazine (Rompun vet; Bayer AG, Leverkusen, Germany) $2 \mathrm{mg} / \mathrm{kg}$. Anesthesia was maintained by continuous intravenous infusion of propofol $(0.1-0.2 \mathrm{mg} / \mathrm{kg}$ body weight per minute, Diprivan; AstraZeneca, Molndal, Sweden) in combination with intermittent fentanyl (0.02 $\mu \mathrm{g} / \mathrm{kg}$ body weight, Leptanal; Lilly, France) and atracurium besylate (0.2-0.5 mg/kg body weight, Tracrium; Glaxo, Täby, Sweden).

The pigs were surgically prepared for TNP therapy. The sternotomy was performed on the left side, lateral to the midline in the upper part of the sternum, because of the prominent pectus carinatum of the pig sternum. Cutting the sternum on the left side of the midline is the standard surgical procedure of our group when creating a porcine sternotomy wound. The left hemisternum was elevated and the left ITA was harvested as a pedicle and removed. The heart was covered by four layers of paraffin gauze dressing (Jelonet; Smith \& Nephew, Hull, United Kingdom). A polyurethane foam dressing was placed between the sternal edges, and two noncollapsible drainage tubes were inserted into the foam. The open wound was then sealed with a transparent adhesive drape. The drainage tubes were connected to a purpose-built vacuum source (VAC pump unit, KCI, Austin, Tex), which was set to deliver a continuous pressure of $-75,-125$ or $-175 \mathrm{~mm} \mathrm{Hg}$. For details, see Wackenfors and associates, ${ }^{19}$ where identical settings were used. The surgical procedure was performed approximately 3 hours before the MRI. This is for logistic reasons, inasmuch as we cannot operate on the animal in the MRI facility.

\section{MRI}

MRI was performed with a 1.5-T scanner (Philips Intera, Best, The Netherlands).

MRI T2-STIR imaging. The amount of fluid in the wound edge tissue was quantified as the MRI T2-STIR signal intensity ratio. Increased T2-STIR signal is typically interpreted as a measure of interstitial fluid as seen in edema or as the presence of fresh intravascular blood. Thus, an increasing amount of fluid and/or blood in an area would accordingly result in a higher T2-STIR signal intensity ratio. T2-STIR imaging was undertaken in a transverse plane at the midventricular level during end-expiratory apnea with a T2STIR sequence. Typical imaging parameters were as follows: electrocardiogram triggering $=$ no, acquired spatial resolution $=0.7 \times$ $0.7 \times 15 \mathrm{~mm}$, repetition time $(\mathrm{TR})=368.6 \mathrm{~ms}$, echo time $(\mathrm{TE})=$ $100.0 \mathrm{~ms}$, SENSE (SENSitivity Encoding) factor $=2$, averages $=$ 4 , spectral fat suppression $=$ on. Images were acquired before TNP and after $0.5,1,1.5,2,2.5,3,4,5,6,7,8,9,10,12,14,16$, $18,20,25,30,35$, and 40 minutes of $-125 \mathrm{~mm} \mathrm{Hg}$ TNP therapy, respectively.

MRI flow imaging in the ITA. Blood flow was measured in the right ITA and the effects of TNP were evaluated by MRI flow quantification. MRI flow quantification involves data acquisition during typically 15 consecutive heartbeats during end-expiratory breath hold, yielding the instantaneous flow for 40 time points over one cardiac cycle. This technique has high spatial and temporal resolution, and blood flow can therefore be quantified with high accuracy. ${ }^{20}$ MRI was performed in a transverse plane at the midventricular level, bisecting the artery. Image acquisition was undertaken during endexpiratory apnea with a retrospectively electrocardiogram-triggered turbo field echo phase contrast velocity encoded sequence. Typical imaging parameters were as follows: acquired spatial resolution $=$ $0.8 \times 0.8 \times 10 \mathrm{~mm}, \mathrm{TR}=5.5 \mathrm{~ms}, \mathrm{TE}=3.8 \mathrm{~ms}$, velocity encoding gradient $=20 \mathrm{~cm} / \mathrm{s}$, SENSE factor $=2$. Images were acquired twice before application of TNP and after 30 seconds and 60 seconds of application of $-75,-125$, and $-175 \mathrm{~mm} \mathrm{Hg} \mathrm{TNP}$, respectively. Imaging for different pressures was performed according to a Latin square scheme to minimize carryover effects. The average of the two baseline acquisitions was taken as the baseline value.

\section{Image Analysis}

Quantification of the T2-STIR signal intensity ratio. Analysis of tissue properties from T2-STIR images was undertaken with freely available software (ImageJ version 1.36b, http://rsb.info.nih.gov/ij/). 
A manually placed irregular region of interest (ROI) was positioned in the right and left medial sternal edge, right and left medial part of the pectoral muscle, and in a dorsally located skeletal muscle as a remote reference (Figure 1). ROIs were all between 10 and 15 $\mathrm{mm}^{2}$ and mean signal intensity within the ROI was quantified. Mean signal intensity for 8 pigs for each time point was analyzed for each side of both the sternum and pectoral muscle and expressed as a signal intensity ratio in relation to remote muscle tissue.

MRI flow quantification in the ITA. Flow quantification was undertaken with freely available software (Segment version 1.464, http://segment.heiberg.se/). All flow was quantified as milliliters per minute. Baseline flow was quantified as the mean of two measurements and subsequent measurements were expressed as percent of the baseline measurement (Figure 2).

\section{Calculation and Statistics}

The experiments were performed on 8 pigs. Statistical analysis was performed by the Mann-Whitney test. Values are presented as means \pm the standard error on the mean (SEM).

\section{Results}

\section{T2-STIR Signal Intensity Ratio Before TNP Application}

Before application of TNP at $-125 \mathrm{~mm} \mathrm{Hg}$, the T2-STIR signal intensity ratio was similar for the right and left pectoral muscles (right, $1.1 \pm 0.1$; left, $0.9 \pm 0.1 ; P=.27$; Figure 3). For the sternum, a higher T2-STIR signal intensity ratio could be observed on the right side, where the vasculature was intact, compared with the left side, which had been devascularized (right, $2.6 \pm 0.2$; left, $1.3 \pm 0.1 ; P=$ .0003 ; Figure 3). This indicates a higher level of tissue fluid/blood content on the right side.

\section{T2-STIR Signal Intensity Ratio Changes on TNP Application}

TNP application at $-125 \mathrm{~mm} \mathrm{Hg}$ elicited an immediate increase in the T2-STIR signal intensity ratio for the sternal bone. This increase was more pronounced in the left hemisternum (before TNP, $1.3 \pm 0.1$; after 4 minutes of TNP, $2.3 \pm 0.3 ; P=.002$ ), which had been devascularized, than in the right hemisternum (before TNP, $2.6 \pm 0.2$; after 4 minutes of TNP, $2.7 \pm 0.3 ; P=.96$ ), where the vasculature was intact (Figure 4).

For the pectoral muscle, there was an increase in T2-STIR signal intensity ratio on application of TNP at $-125 \mathrm{~mm} \mathrm{Hg}$ that was similar on the right and left sides (Figure 4), although the left side did not reach statistical significance (right before TNP, $1.1 \pm 0.1$, and after 4 minutes of TNP, $1.4 \pm$ $0.1 ; P=.049$; left before, $0.9 \pm 0.1$, and after 4 minutes of TNP, $1.2 \pm 0.2 ; P=.195$ ).

For all wound edge tissues studied, the increase in T2STIR signal intensity ratio appeared immediately, leveled off after 4 minutes, and then remained unchanged for the ensuing 40 minutes (Figure 4).

A control experiment was performed, in which T2-STIR signal intensity was examined in the right and left pectoral muscles and sternum, over a period of 40 minutes, without prior TNP application. The results showed unaltered signal intensity ratios over time, suggesting that the increase in wound edge tissue fluid content is due to TNP application.

\section{ITA Blood Flow}

The blood flow in the right ITA was similar before and after application of TNP at $-75,-125$, and $-175 \mathrm{~mm} \mathrm{Hg}$ (before
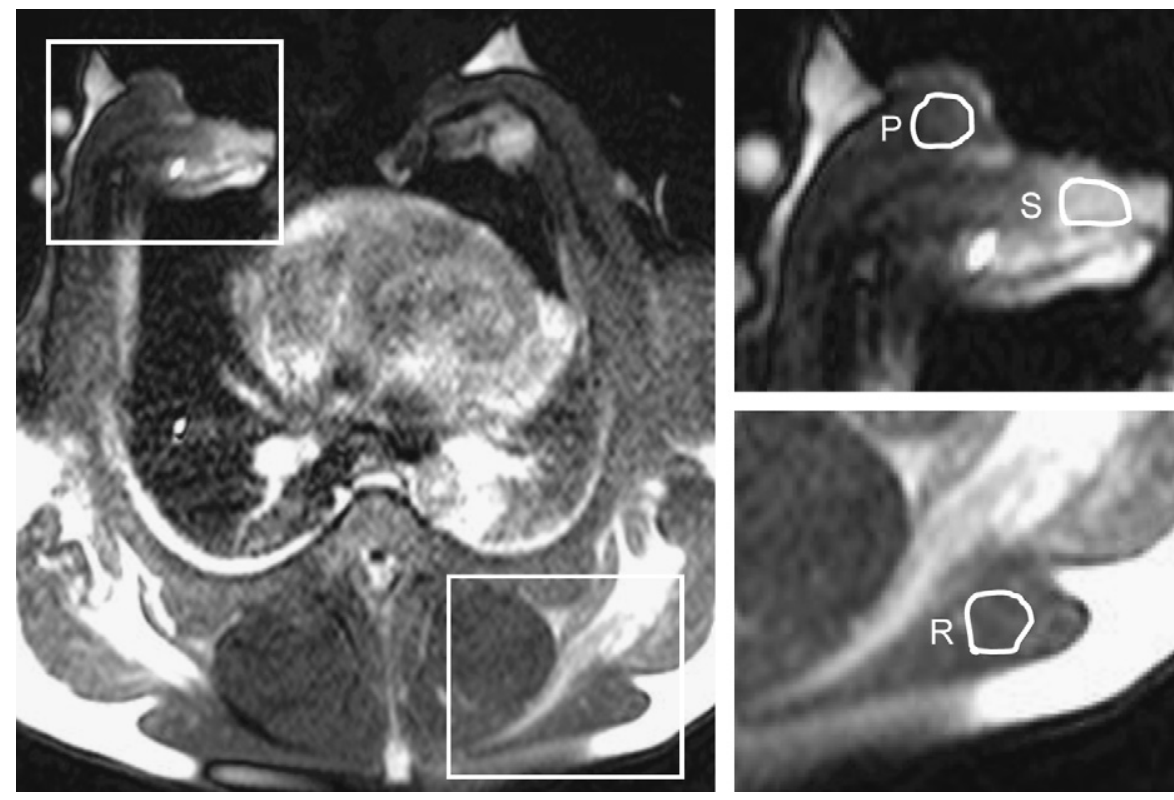

Figure 1. The left image show a transverse T2-STIR MRI through the thorax of a pig with an open sternotomy wound. The right images show an enlargement of the two insets, which illustrate the position of the regions of interest used to measure the signal intensity in the pectoral muscle $(P)$, sternal wound edge (S), and remote skeletal muscle (R). The ITA has been harvested on the left side while being intact on the right side. Note the hyperintense signal in the right sternal wound edge compared with the left. 

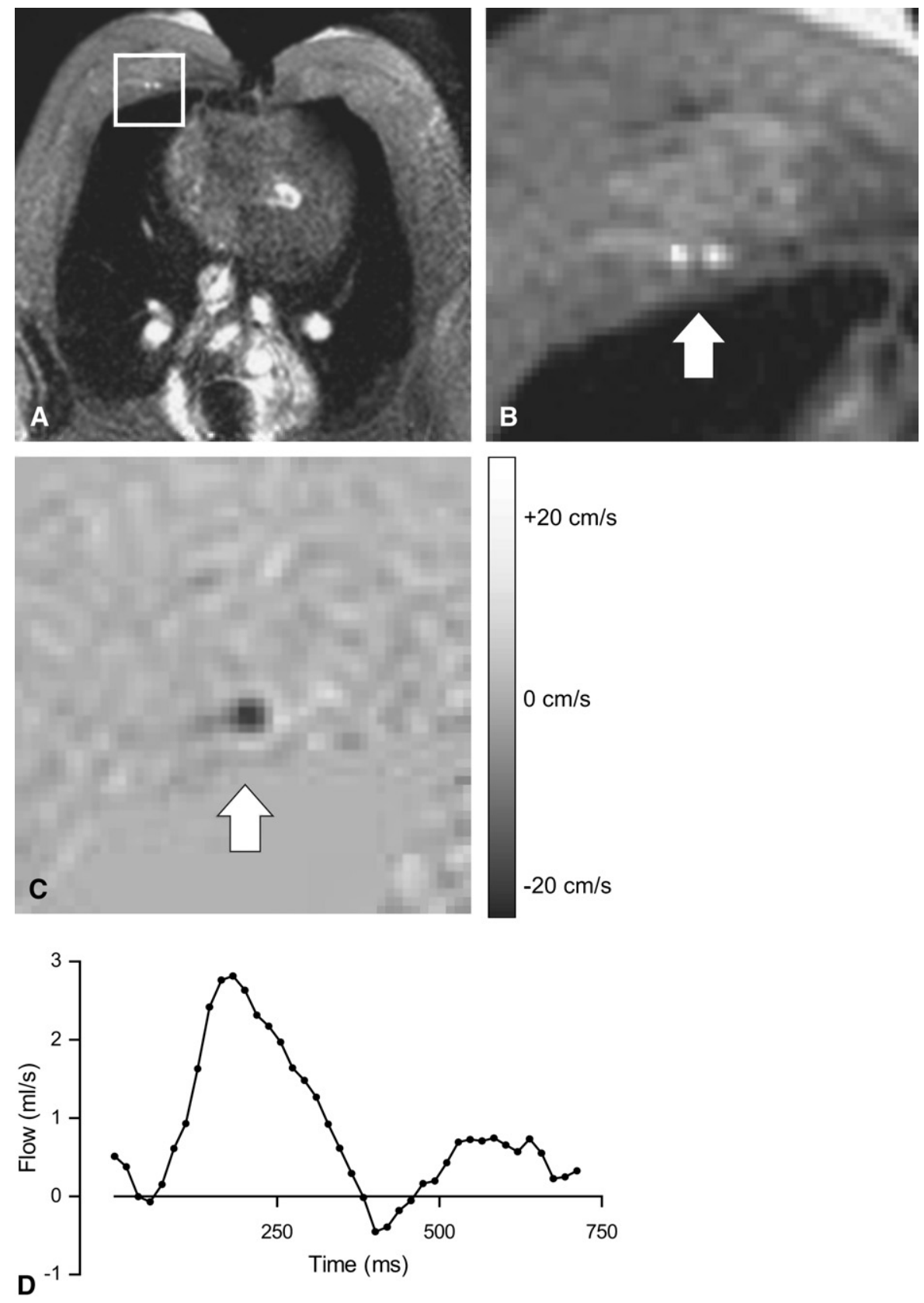

Figure 2. Quantification of right ITA blood flow using MRI. A, Image in a transverse plane. $B$, Enlargement of the inset in panel $A$, showing a cross section of the right ITA at peak systolic flow (arrow). C, Simultaneously acquired velocity data for tissue moving through the image plane according to the gray scale to the right, ranging from -20 to $+20 \mathrm{~cm} / \mathrm{s}$. Bright signal intensities correspond to velocity into the image plane and dark signal intensities correspond to velocity in the opposite direction. The cross section of the artery was delineated for all 40 time frames throughout the cardiac cycle, whereby the average flow at each time point could be quantified (D).
TNP: $37 \pm 10 \mathrm{~mL} / \mathrm{min}$; after 1 minute of TNP at $-125 \mathrm{~mm}$ $\mathrm{Hg}: 36 \pm 12 \mathrm{~mL} / \mathrm{min} ; P=1.0$; Figure 5).

\section{Discussion}

TNP has remarkable effects on the healing of poststernotomy mediastinitis. ${ }^{10}$ A number of studies have examined the mechanisms involved in the TNP healing effects, mainly in peripheral wounds, and have shown reduced bacterial counts, increased wound edge microvascular blood flow, and granulation tissue formation. ${ }^{16-19}$ In poststernotomy mediastinitis, osteitis is a complicating factor. This is the first study to examine effects of TNP on the fluid and/or blood content in the sternal bone. The current study has used MRI to show that TNP increases sternotomy wound edge tissue fluid and/or blood content but does not affect ITA blood flow.

\section{T2-STIR Signal Intensity Ratio Before TNP Application}

Before the application of TNP, a lower T2-STIR signal intensity ratio could be observed for the left than for the right hemisternum, indicating lower levels of fluid on the left side. This may possibly be due to the left sternal wound edge being 

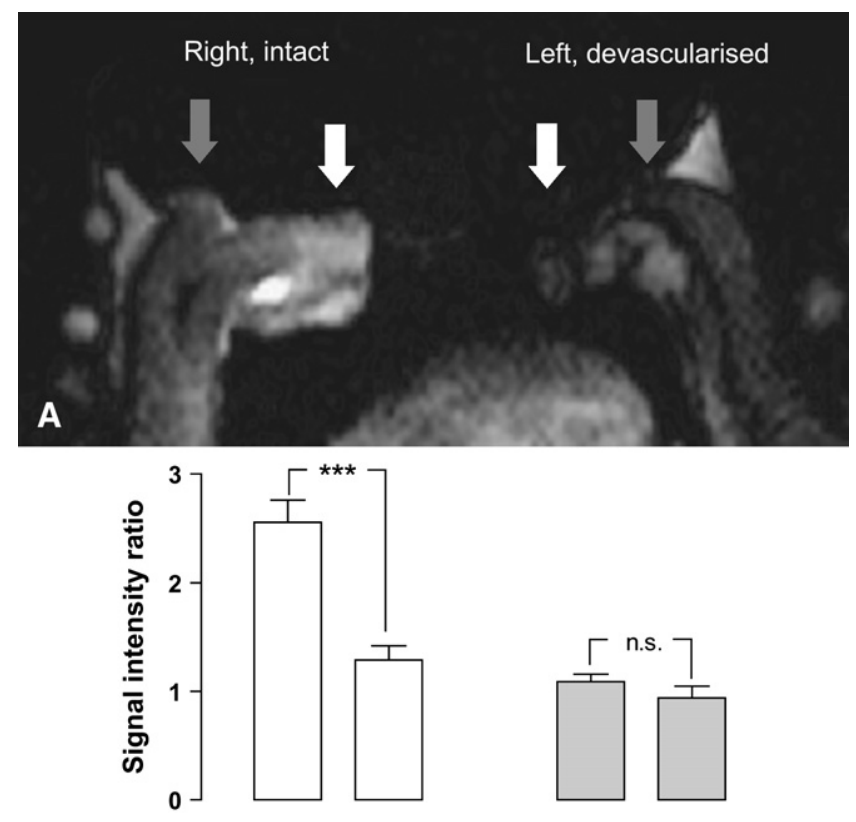

B

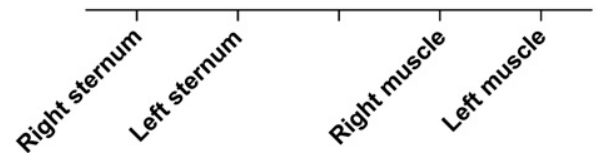

Figure 3. Mean T2-STIR signal intensity ratios on both sides of a sternotomy wound before the application of negative pressure ( $n=8$ pigs). On the right side, the ITA was intact while (right, intact) on the left side it had been removed (left, devascularized). A, Transverse T2 STIR MRI through the sternum (white arrows) and the pectoral muscle (gray arrows). The signal intensity was measured in the sternum and pectoral muscle on the right and left sides, expressed as a ratio to the remote skeletal muscle as shown in Figure 1. The results are presented in panel B. Note the low signal intensity in the sternum on the left side, where the ITA had been removed. Error bars denote SEM. ${ }^{* *}$ denotes $P<.001$ and n.s. denotes $P>.05$.

devascularized. Most conspicuously, this would be due to the ITA being harvested on the left side. However, in a control experiment, in which both the right and left ITAs were intact, there was no obvious difference in the T2-STIR signal intensity ratio between the right and left hemisternums (data not shown). Except for the left ITA harvesting, the left hemisternum was devascularized by cutting the perforating arteries from the pectoral muscle on the left side. This was due to performing the sternotomy "left-sided," lateral to the midline in the upper part of the sternum, because of the prominent pectus carinatum in the pig sternum. Cutting the sternum on the left side of the midline is the standard surgical procedure when we create a porcine sternotomy wound. In conclusion, the lower observed T2-STIR signal intensity ratio for the left side is presumably due to lower amounts of blood in the wound edge tissue that is devascularized. The present study is not entirely conclusive regarding which of the sternal vascular collateral systems is of most importance.

\section{T2-STIR Signal Intensity Ratio Change on TNP Application}

Application of negative pressure induced an immediate increase in the T2-STIR signal intensity ratio for the wound edge tissue. The increase in T2-STIR signal intensity ratio was more pronounced for the left hemisternum than for the right hemisternum. The reason for this difference may be the initial high levels of fluid on the right side. On the one hand, a tissue that already has a substantial fluid content may not have the potential to harbor even greater amounts. On the other hand, a tissue that initially has a lesser amount of fluid retains the potential to increase the amount of fluid.

\section{Mechanisms Governing the T2-STIR Signal Intensity Ratio Increase on TNP Application}

The mechanism by which the wound edge fluid content is increased can only be speculated on. An increased T2STIR signal is commonly interpreted as edema, although blood also has a high signal intensity, and an increased amount of blood in an area will thereby result in a higher T2-STIR signal intensity ratio. TNP therapy is known to cause an immediate increase in wound edge microvascular blood flow. The blood flow to wounds on the backs of pigs was shown to increase four times above the baseline values when $-125 \mathrm{~mm} \mathrm{Hg}$ was applied..$^{17} \mathrm{In}$ a recent study, the cutaneous blood flow in healthy intact forearm skin was found

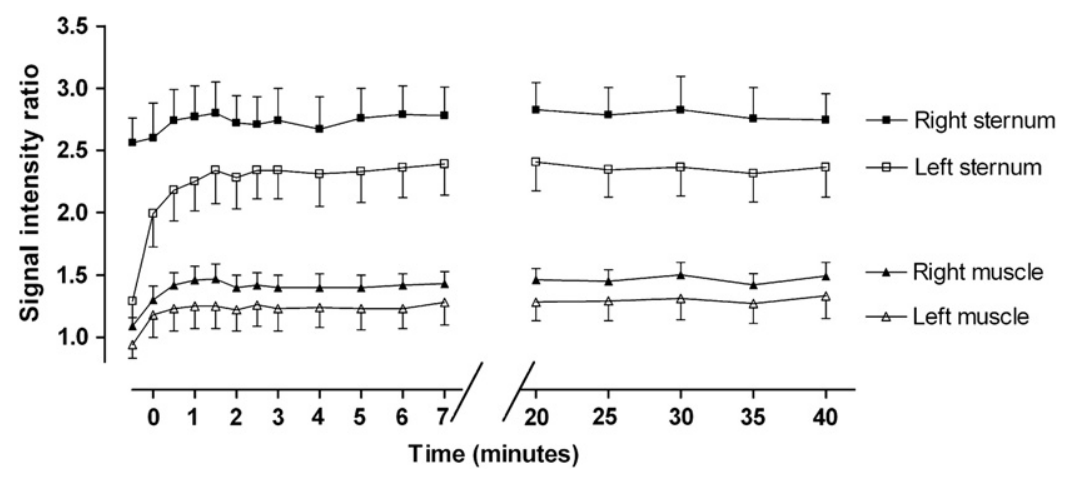

Figure 4. Mean T2-STIR signal intensity ratios before and during the application of negative pressure $(-125 \mathrm{~mm} \mathrm{Hg})(\mathrm{n}=8$ pigs). Signal intensities were measured as described in Figure 1. The signal intensity ratio was calculated for right sternum/remote, left sternum/remote, right muscle/remote, and left muscle/remote. Note the initial pronounced increase in signal intensity in the left sternum, indicating an increase in tissue fluid content on TNP application. Error bars denote SEM. 


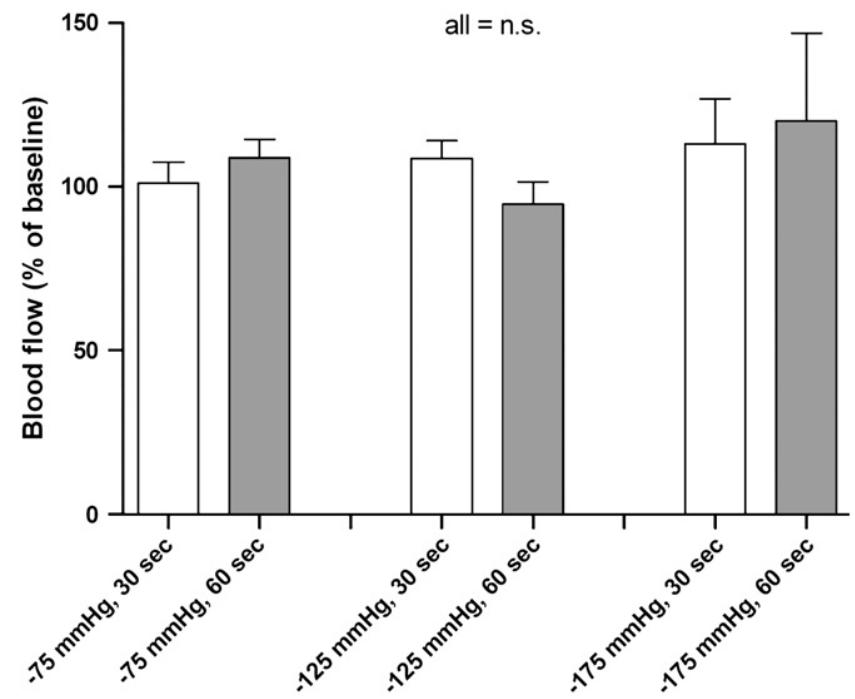

Figure 5. Blood flow in the right ITA after application of negative pressure measured by MRI flow quantification as shown in Figure 2 ( $n=8$ pigs). Measurements were performed before (baseline) and 30 and 60 seconds after application of negative pressure. The results were calculated as percent change compared with baseline and are expressed as mean values \pm SEM. The results suggest that the ITA blood flow is not altered by the application of topical negative pressure. n.s. denotes $\boldsymbol{P}>.05$.

to increase by application of TNP. ${ }^{21}$ In a laser Doppler study, $\mathrm{we}^{19}$ recently showed increased blood flow in the pig sternotomy wound edge by TNP therapy. The blood flow effects of TNP for longer periods of time have been studied by Chen and associates, ${ }^{22}$ where wounds were created by the removal of full-thickness skin on the back of rabbit ears. Blood flow velocity in the capillaries was found to increase immediately after application of negative pressure. After 4 minutes, there was a peak in blood flow velocity and it remained at a high level even after 20 minutes. ${ }^{22}$ Our findings are in accordance with these results and show an immediate increase in T2STIR signal intensity ratio, which leveled off after 4 minutes and then remained unchanged for the ensuing 40 minutes. TNP induces mechanical stress, and a pressure gradient between the wound and the surrounding tissue may force blood to the wound, increase blood flow velocity, dilate capillaries, and open up the capillary bed. ${ }^{22,23}$ Blood is thereby recruited to the wound edge tissue during TNP therapy and may result in increased T2-STIR signal intensity ratio.

There are two reasons why we draw the conclusion that the increase in wound edge tissue fluid content is due to TNP application and not an unspecific effect resulting from the sternotomy and subsequent edema and necrosis that may have developed over time in the ischemic sternal wound edge tissue. First, in a control experiment, without TNP application, the wound edge tissue fluid contents were constant over a period of 40 minutes. Second, for logistic reasons, the sternotomy was performed approximately 3 hours before the MRI was started (see Methods). We therefore assume that the surgery-induced edema would have reached a steady state level, or occur at a very slow rate, once the MRI was started.

\section{TNP Effects on Blood Flow in the ITA}

A number of studies have been undertaken to examine the microvascular blood flow to the wound edge, and it has been assumed that the blood flow-stimulating effects are induced via the opening of capillary beds. No study has yet been performed to examine whether TNP also increases blood flow in conductance arteries. We used MRI flow quantification to measure blood flow in the ITA during TNP therapy. MRI is the in vivo reference standard ${ }^{24}$ for assessment of flow in blood vessels based on the excellent accuracy and low variability of the measurements. ${ }^{25,26}$ Blood flow in the right ITA was similar before and after the application of -75 , -125 , and $-175 \mathrm{~mm} \mathrm{Hg}$. The ITA is located 2 to $3 \mathrm{~cm}$ from the sternotomy wound edge that is exposed to the negative pressure. Laser Doppler studies have proven that this distance from the wound edge is where TNP exerts its maximal stimulatory effect on the microvasculature. ${ }^{19}$ However, our results indicate that we do not have a direct effect on conductance arteries, such as the ITA, at this distance from the vacuum source. The observed increase in T2-STIR signal intensity ratios likely reflects fluid and blood that may be derived from vascular beds other than the ITA. Furthermore, TNP creates a pressure gradient that presumably draws fluid from the surrounding bone marrow to the marrow near the sternal wound edge and into the vacuum source.

\section{Limitations of the Study}

One limitation of the present study was that the experiments were performed in a noninfected sternotomy wound model. Indeed, the indication for TNP in cardiac surgery is mediastinitis. TNP therapy has been shown to be advantageous in infected or nonhealing chronic wounds, but not in acutely injured wounds. ${ }^{27}$ The microvascular tissue perfusion is often reduced in an infected wound, leading to decreased nutrition of the wound margins. TNP therapy is known to improve microvascular blood flow to the wound edge, ${ }^{19}$ an observation that is supported by the present study. The effects of TNP therapy can only be speculated about, but may be even more pronounced in an infected wound than in this experimental setup employing a noninfected acute sternotomy wound

\section{Conclusions}

TNP causes an immediate increase in the T2-STIR signal intensity ratio for the wound edge, suggesting increased amounts of fluid and/or blood in the tissue. Blood flow in the right ITA was not affected by TNP, indicating no direct effect on conductance arteries, in this case the ITA. The observed increase in T2-STIR signal intensity ratios for the wound edge tissues on TNP application is presumably related 
to increased microvascular blood flow, as previously seen in laser Doppler studies, ${ }^{17,19,28}$ or fluid drawn to the sternal edge from the surrounding bone marrow. Blood and fluid are probably derived from vascular beds other than the ITA. Thus, TNP creates a pressure gradient between the wound edge tissue and the vacuum source. This effect probably moves fluid from the surrounding tissue to the sternal wound edge and into the vacuum source. This "endogenous drainage" may be one possible mechanism by which osteitis is resolved by TNP in poststernotomy mediastinitis.

We thank Thomas Krabatsch, MD, PhD, and Christof Stamm, $\mathrm{MD}, \mathrm{PhD}$, at the Deutsches Herzzentrum Berlin, Berlin, Germany, for their valuable comments.

\section{References}

1. Lu X, Chen S, Li X, et al. The experimental study of the effects of vacuum-assisted closure on edema and vessel permeability of the wound. Chin J Clin Rehab. 2003;7:1244-5.

2. Ridderstolpe L, Gill H, Granfeldt H, Ahlfeldt H, Rutberg H. Superficial and deep sternal wound complications: incidence, risk factors and mortality. Eur J Cardiothorac Surg. 2001;20:1168-75.

3. Ståhle E, Tammelin A, Bergström R, Hambreus A, Nyström SO, Hansson HE. Sternal wound complications-incidence, microbiology and risk factors. Eur J Cardiothorac Surg. 1997;11:1146-53.

4. Borger MA, Rao V, Weisel RD, Ivanov J, Cohen G, Scully HE, et al. Deep sternal wound infection: risk factors and outcomes. Ann Thorac Surg. 1998;65:1050-6.

5. Grossi EA, Culliford AT, Krieger KH, Kloth D, Press R, Baumann FG, et al. A survey of 77 major infectious complications of median sternotomy: a review of 7,949 consecutive operative procedures. Ann Thorac Surg. 1985;40:214-23.

6. Krabatsch T, Fleck E, Hetzer R. Treating poststernotomy mediastinitis by transposition of the greater omentum: late angiographic findings. J Card Surg. 1995;10:46-51.

7. Durandy Y, Batisse A, Bourel P, Dibie A, Lemoine G, Lecompte Y. Mediastinal infection after cardiac operation: a simple closed technique. J Thorac Cardiovasc Surg. 1989;97:282-5.

8. Lee AB Jr, Schimert G, Shaktin S, Seigel JH. Total excision of the sternum and thoracic pedicle transposition of the greater omentum; useful strategems in managing severe mediastinal infection following open heart surgery. Surgery. 1976;80:433-6.

9. Shibata T, Hattori K, Hirai H, Fujii H, Aoyama T, Seuhiro S. Rectus abdominis myocutaneous flap after unsuccessful delayed sternal closure. Ann Thorac Surg. 2003;76:956-8.

10. Domkowski PW, Smith ML, Gonyon DL Jr, Drye C, Wooten MK, Levin LS, et al. Evaluation of vacuum-assisted closure in the treatment of poststernotomy mediastinitis. J Thorac Cardiovasc Surg. 2003;126: 386-90.

11. Mokhtari A, Petzina R, Gustafsson L, Sjögren J, Malmsjö M, Ingemansson R. Sternal stability at different negative pressures during vacuum-assisted closure therapy. Ann Thorac Surg. 2006;82:1063-7.

12. Fleck TM, Fleck M, Moidl R, Czerny M, Koller R, Giovanoli P, et al. The vacuum-assisted closure system for the treatment of deep sternal wound infections after cardiac surgery. Ann Thorac Surg. 2002;74: 1596-600; discussion 1600 .

13. Doss M, Martens S, Wood JP, Wolff JD, Baier C, Moritz A. Vacuumassisted suction drainage versus conventional treatment in the management of poststernotomy osteomyelitis. Eur J Cardiothorac Surg. 2002;22:934-8.

14. Sjögren J, Gustafsson R, Nilsson J, Malmsjö M, Ingemansson R. Clinical outcome after poststernotomy mediastinitis: vacuum-assisted closure versus conventional treatment. Ann Thorac Surg. 2005;79:2049-55.

15. Sjögren J, Nilsson J, Gustafsson R, Malmsjö M, Ingemansson R. The impact of vacuum-assisted closure on long-term survival after poststernotomy mediastinitis. Ann Thorac Surg. 2005;80:1270-5.

16. Argenta LC, Morykwas MJ. Vacuum-assisted closure: a new method for wound control and treatment: clinical experience. Ann Plast Surg. 1997; 38:563-76; discussion 577.

17. Morykwas MJ, Argenta LC, Shelton-Brown EI, McGuirt W. Vacuumassisted closure: a new method for wound control and treatment: animal studies and basic foundation. Ann Plast Surg. 1997;38:553-62.

18. Petzina R, Gustafsson L, Mokhtari A, Ingemansson R, Malmsjö M. Effect of vacuum-assisted closure on blood flow in the peristernal thoracic wall after internal mammary artery harvesting. Eur J Cardiothorac Surg. 2006;30:85-9.

19. Wackenfors A, Gustafsson R, Sjögren J, Algotsson L, Ingemansson R, Malmsjö M. Blood flow responses in the peristernal thoracic wall during vacuum-assisted closure therapy. Ann Thorac Surg. 2005;79:1724-30; discussion $1730-1$.

20. Chatzimavroudis GP, Zhang H, Halliburton SS, Moore JR, Simonetti OP, Schvartzman PR, et al. Clinical blood flow quantification with segmented $\mathrm{k}$-space magnetic resonance phase velocity mapping. J Magn Reson Imaging. 2003;17:65-71.

21. Timmers MS, Le Cessie S, Banwell P, Jukema GN. The effects of varying degrees of pressure delivered by negative-pressure wound therapy on skin perfusion. Ann Plast Surg. 2005;55:665-71.

22. Chen SZ, Li J, Li XY, Xu LS. Effects of vacuum-assisted closure on wound microcirculation: an experimental study. Asian J Surg. 2005; 28:211-7.

23. Urschel JD, Scott PG, Williams HT. The effect of mechanical stress on soft and hard tissue repair; a review. Br J Plast Surg. 1988;41:182-6.

24. Pennell DJ, Sechtem UP, Higgins CB, Manning WJ, Pohost GM, Rademakers FE, et al. Clinical indications for cardiovascular magnetic resonance (CMR): Consensus Panel report. Eur Heart J. 2004;25: 1940-65.

25. Arheden H, Saeed M, Törnqvist E, Lund G, Wendland MF, Higgins CB, et al. Accuracy of segmented MR velocity mapping to measure small vessel pulsatile flow in a phantom simulating cardiac motion. J Magn Reson Imaging. 2001;13:722-8.

26. Kuehne T, Yilmaz S, Schulze-Neick I, Wellnhofer E, Ewert P, Nagel E, et al. Magnetic resonance imaging guided catheterisation for assessment of pulmonary vascular resistance: in vivo validation and clinical application in patients with pulmonary hypertension. Heart. 2005;91:1064-9.

27. Miller Q, Bird E, Bird K, Meschter C, Moulton MJ. Effect of subatmospheric pressure on the acute healing wound. Curr Surg. 2004;61:205-8.

28. Wackenfors A, Sjögren J, Gustafsson R, Algotsson L, Ingemansson R, Malmsjö M. Effects of vacuum-assisted closure therapy on inguinal wound edge microvascular blood flow. Wound Repair Regen. 2004; 12:600-6. 